\title{
Thermally conductive and electrically insulating EVA composite encapsulants for solar photovoltaic (PV) cell
}

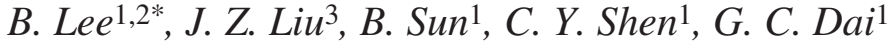 \\ ${ }^{1}$ National Key Laboratory of Chemical Engineering, East China University of Science and Technology, \\ 130 Meilong Road, Shanghai 200237, P. R. China \\ ${ }^{2}$ School of Mechanical and Power Engineering, East China University of Science and Technology, \\ 130 Meilong Road, Shanghai 200237, P. R. China \\ ${ }^{3}$ Shanghai Solar Energy Science and Technology Co., Ltd., West Gangde Road, Shanghai 200336, P. R. China
}

Received 26 February 2008; accepted in revised form 26 March 2008

\begin{abstract}
A new way of improving the heat dissipating ability and PV efficiency of the solar cells by enhancing the thermal conductivity of the rear EVA layer was reported. The thermal conductivity, electrical resistivity, degree of curing of the EVA encapsulating composites and the PV efficiency of the solar cells are investigated. Filling with the thermal conductive fillers enhances the thermal conductivity of the composites effectively. The thermal conductivity of the filler influences significantly the thermal conductivity of the composite at high filler loading (greater than $20 \mathrm{vol} \%$ ). Thermal conductivities of the composites filled with $\mathrm{SiC}, \mathrm{ZnO}$ or $\mathrm{BN}$ reach respectively $2.85,2.26$ and $2.08 \mathrm{~W} / \mathrm{m} \cdot \mathrm{K}$ at filler content of $60 \mathrm{vol} \%$. The composites filled with $\mathrm{ZnO}$ or $\mathrm{BN}$ exhibit superior electrical insulation to those filled with $\mathrm{SiC}_{\text {or }} \mathrm{Al}_{2} \mathrm{O}_{3}$. $\mathrm{ZnO}$ can promote the cross-linking reaction of the EVA matrix. The test results indicated that the EVA composite encapsulating rear films filled with thermal conductive fillers are able to improve the PV efficiency and the heat dissipating ability of the solar cell effectively.
\end{abstract}

Keywords: thermal properties, EVA composite, electrically insulating, encapsulant, solar cell

\section{Introduction}

Photovoltaics represent a clean, silent, renewable alternative energy source, potentially beneficial to the environment by preventing greenhouse gases from being produced and entering the atmosphere. With increasing energy demand and environmental pollution, better utilization of solar energy is considered to be the best way for energy generation $[1,2]$. In fact, only a small fraction of the incoming sunlight striking the cell is converted into electrical energy (a typical efficiency value for crystalline-Si cells is $14-17 \%$ ) ; most of the absorbed solar radiation energy by solar cells will be converted into thermal energy and may cause the cells junction temperature to rise unless the heat is efficiently dis- sipated to the environment $[3,4]$. The photovoltaic cell efficiency decreases with increasing cell temperature because of the negative temperature coefficient of crystalline-Si (about $-0.4 \sim-0.5 \% / \mathrm{K}$ ). The cells will also exhibit long-term degradation if the temperature exceeds a certain limit $[5,6]$. Therefore, some technology means have been developed for cooling the solar cells, such as hybrid photovoltaic/thermal solar system (PV/T) [7-9] and jet impingement cooling device $[4,10]$.

In practical use, most solar cells are in fact encapsulated into a 'sandwich' structure that typically consists of Glass/Ethylene-vinyl acetate (EVA)/ ARC-Si/EVA/Tedlar (see Figure 1). The sizes and properties of each layer in encapsulated cells are

*Corresponding author, e-mail: binlee10@yahoo.cn

(C) BME-PT and GTE 


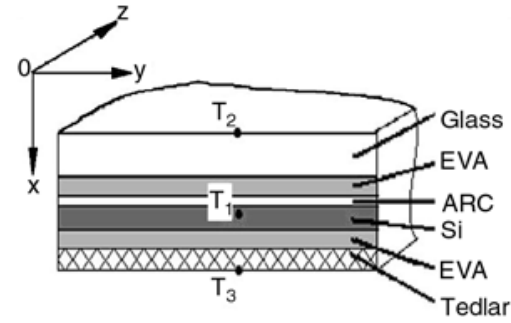

Figure 1. The configuration of laminated $\&$ encapsulated Si solar cells [11] (ARC: anti-reflecting coating, Tedlar: a kind of composite film of PET-PVF from DuPont)

Table 1. The sizes and properties of each layer in encapsulated Si solar cells

\begin{tabular}{|c|l|c|c|}
\hline No. & Layer & $\begin{array}{c}\text { Thickness } \boldsymbol{\delta} \\
{[\mathbf{m m}]}\end{array}$ & $\begin{array}{c}\text { Thermal conductivity k } \\
{\left[\mathbf{W} \cdot \mathbf{m}^{-1} \cdot \mathbf{K}^{-1}\right]}\end{array}$ \\
\hline 1 & Glass & 3.0 & $0.98^{*}$ \\
\hline 2 & EVA & 0.5 & $0.23^{*}$ \\
\hline 3 & ARC & $(0.06-0.1) \cdot 10^{-3}$ & 1.38 \\
\hline 4 & Si & $0.25-0.4$ & 148 \\
\hline 5 & EVA & 0.5 & $0.23^{*}$ \\
\hline 6 & Tedlar & 0.1 & $0.36^{*}$ \\
\hline
\end{tabular}

*measured value

listed in Table 1 [11]. Analyzing the properties and sizes in Table 1, it is not difficult to understand that the EVA is the main thermal resistance layer in encapsulated solar cells. So, we hope to improve the heat dissipating ability and PV efficiency of the solar cells by enhancing the thermal conductivity of rear EVA layer. To the authors' knowledge publications related to this aspect have not appeared.

Polymers filled with thermally conductive fillers are emerging as a cost effective way to copy with thermal management issues. The incorporation of highly thermal conductive fillers in polymers to develop high performance thermal conductive encapsulants or thermal interface materials has been mostly desired $[12,13]$. A thermal conductivity value of $2.3 \mathrm{~W} /(\mathrm{m} \cdot \mathrm{K})$ for epoxy resin filled with boron nitride at the loading of $31 \mathrm{vol} \%$ was reported, a high thermal conductivity of $4.5 \mathrm{~W} /(\mathrm{m} \cdot \mathrm{K})$ for $80 \mathrm{vol} \%$ aluminum nitride filled epoxy was also achieved [13]. The thermal conductivity of com- posites is determined by the shape, the size distribution and surface treatment of the filler [14]. Besides the clarity, non-yellowing and dimensional stability, the electrical insulation, curing performance and adhesive processability are also very important to the capsulant of solar cell.

In this paper, we introduce a new way to improve the heat dissipating ability and PV efficiency of the solar cells. The EVA encapsulating composites of solar cell were filled with thermally conductive fillers. The electrical resistivity, thermal conductivity and curing degree of the EVA encapsulating composites are investigated. The PV efficiency of the solar cells encapsulated with the EVA composites or the contrast EVA films on the rear are reported and compared .

\section{Experimental}

\subsection{Materials}

The ethylene-vinylacetate (EVA), Elvax-220W, with a melt flow index of $150 \mathrm{~g} / 10 \mathrm{~min}$, vinyl acetate content of $28 \%$ and density of $0.951 \mathrm{~g} / \mathrm{cm}^{3}$, supplied by DuPont chemical company was used in this work. Magnesium oxide $(\mathrm{MgO})$ and aluminium oxide $\left(\mathrm{Al}_{2} \mathrm{O}_{3}\right)$ were obtained from Sinopharm Shanghai Chemical Reagent Co., Ltd. Zinc oxide $(\mathrm{ZnO})$ was obtained from Shanghai Jinghua Chemical Co., Ltd. Silicon carbide (SiC), boron nitride $(\mathrm{BN})$ and aluminium nitride (AlN) were obtained from Shanghai Institute of Ceramics, Chinese Academy of Sciences. The silane coupling agents of glycidoxypropyl trimethoxysilane (KH-560) and amino-propyl triethoxysilane (KH-550) were obtained from Shanghai Yaohua chemical Co., Ltd. The aluminium and titanium composite coupling agent $\left(\mathrm{OL}-\mathrm{AT} 1618, \mathrm{Al}(\mathrm{OR})_{\mathrm{n}}\left(\mathrm{OOCR}^{\prime \prime}\right)_{3-\mathrm{n}} \mathrm{Ti}\left(\mathrm{OR}^{\prime}\right)_{\mathrm{m}}\right.$ $\left.\left(\mathrm{OOCR}^{\prime \prime}\right)_{4-\mathrm{m}}\right)$ was supplied by Shanxi Provincial Institute of Chemical Industry. The titanate coupling agent (NDZ-132, $\left.\left(\mathrm{CH}_{3}\right)_{2} \mathrm{CHOTi}(\mathrm{OOCR})_{3}\right)$ was obtained from Nanjing Shuguang Chemical Co., Ltd., China.

Table 2. The property of fillers [15]

\begin{tabular}{|c|c|c|c|c|c|c|}
\hline & MgO & $\mathbf{A l}_{2} \mathbf{O}_{3}$ & $\mathrm{ZnO}$ & $\mathrm{SiC}$ & BN & AlN \\
\hline Density $\left[\mathrm{g} / \mathrm{cm}^{3}\right]$ & 3.58 & 3.96 & 5.6 & 3.22 & 2.25 & 3.26 \\
\hline Thermal conductivity $\left[\mathrm{W} \cdot \mathrm{m}^{-1} \cdot \mathrm{K}^{-1}\right]$ & 30 & 26 & 34 & 56 & 35 & 31 \\
\hline Average size $[\mu \mathrm{m}]$ & 1.1 & 1.3 & 1.0 & 1.9 & 1.5 & 2.0 \\
\hline Shape & \multicolumn{6}{|c|}{ random grain } \\
\hline
\end{tabular}




\subsection{Surface modification}

In order to ensure filler good dispersion and to improve the interface interaction between the filler and matrix, we used the coupling agents as described above for surface modification of the fillers. The surface modification was carried out as follows: (1) mixing the filler and the coupling agent of $1 \mathrm{wt} \%$ in terms of filler weight in a small amount of isopropyl alcohol at $80^{\circ} \mathrm{C}$ for $2 \mathrm{~h}$, (2) vacuum drying to remove solvent at $85^{\circ} \mathrm{C}$ for $24 \mathrm{~h}$, (3) exposing the filler to ambient air for $4 \mathrm{~h}$, (4) heat treating the filler at $100 / 120^{\circ} \mathrm{C}$ for $4 \mathrm{~h}$. The treated fillers were stored in vacuum dryer.

\subsection{Composite sample preparation}

The EVA and fillers, which were weighed in terms of a certain volume content, were mixed on a tworoll mill (SK-160B, Shanghai Rubber Machine Company, China) at temperature of $90 \pm 5^{\circ} \mathrm{C}$ for 15 minutes; and then the molten compounds were transferred into the mold with the required dimension $(50 \mathrm{~mm}$ diameter and 5-7 $\mathrm{mm}$ thickness for thermal conductivity, $150 \mathrm{~mm}$ diameter and 1$3 \mathrm{~mm}$ thickness for electrical insulation). Pressure up to $10 \mathrm{MPa}$ was applied by hydraulic press (YX25, Shanghai Ximaweili Rubber and Plastic Machine Company, China) and kept for 3 minutes at room temperature. The cylinder sample with $50 \mathrm{~mm}$ diameter and $5-7 \mathrm{~mm}$ thickness was released out of the mold. The samples were polished with sandpaper until surface become smooth. For the EVA encapsulating composite rear film of solar cell, the peroxide (Trogonox 101, Akzo Nobel) of $1.5 \mathrm{wt} \%$ and the coupling agent (KH-560 or OLAT-1618) of $1 \mathrm{wt} \%$ in terms of matrix weight were mixed with EVA and fillers. Pressure up to $10 \mathrm{MPa}$ was applied by hydraulic press and kept for $10-15$ minutes at $80-85^{\circ} \mathrm{C}$ until the thickness of film was about $0.5 \mathrm{~mm}$.

\subsection{Preparation of solar cells}

In this paper, the solar cells are laminated and encapsulated into a typical 'sandwich' structure that consists of Glass/EVA/ARC-Si/Composites rear film/Tedlar (refer to Figure 1). The lamination was done at temperature of $135^{\circ} \mathrm{C}$ for $30 \mathrm{~min}$, under a pressure of $0.07-0.08 \mathrm{MPa}$.

\subsection{Characterization}

The thermal conductivity of composites was measured with an Anter thermal conductivity meter (Quickline-10B, American Anter Corporation) according to ASTM E 1530 (Guarded heat flow meter method).

The electrical resistivity of composites was directly measured with CANY high resistivity meter (ZC-43, Shanghai Cany Precision Instrument Co., Ltd. China).

The curing degree of composites was measured as the ratio of remaining EVA weight to original EVA weight after Soxhlet extracted with toluene at $110^{\circ} \mathrm{C}$ for $12 \mathrm{~h}$.

PV efficiency of the solar cells was evaluated by surveying maximum output power of the solar cells under given irradiation intensity $\left(1000.0 \mathrm{~W} / \mathrm{m}^{2}\right)$ and ambient temperature $\left(25^{\circ} \mathrm{C}\right)$. Surfaces temperatures $\left(T_{2}-\right.$ upper, $T_{3}$ - rear, see Figure 1) were measured with infrared thermometer after $2 \mathrm{~h}$ out'door (the ambient temperature of $27-29^{\circ} \mathrm{C}$ ).

\section{Results and discussion}

\subsection{The effect of fillers on the thermal conductivity of EVA composite}

Various thermally conductive fillers were mixed to EVA matrix in order to improve the thermal conductivity and heat dissipating ability of the EVA encapsulating composite rear film of the solar cell. The thermal conductivities of EVA composites filled with different fillers are shown in Figure 2. It can be seen that all thermal conductivities of the EVA composites rise gradually with the volume contents of fillers increasing. The thermal conductivities of composites rise very slowly at low filler

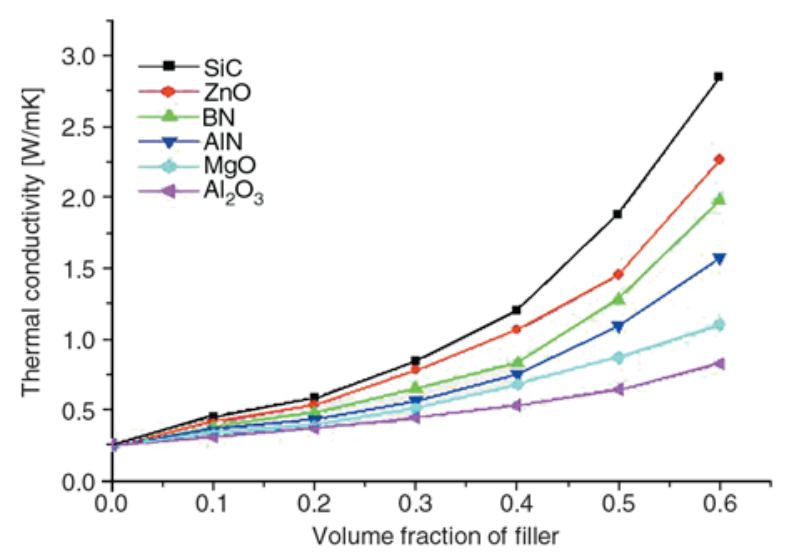

Figure 2. Thermal conductivity of the EVA composites 
loading, because the thermally conductive filler particles are surrounded by matrix can not touch each other and the matrix has high thermal resistance. When the loading of thermally conductive filler exceeds $20 \mathrm{vol} \%$, the filler particles easily to touch each other and form more compact packing heat conductive structure, and that results in thinner layers of matrix between the particles, which decreases the contact heat resistance; so, the heat conductive filler have a greater effect on the thermal conductivity of the composites than that at low filler loading, and the thermal conductivity increases rapidly.

However, there are marked differences between the thermal conductivities of the EVA composites filled with differet fillers at high filler loading (greater than $20 \mathrm{vol} \%$ ). The thermal conductivities of the composites filled with $\mathrm{SiC}, \mathrm{ZnO}$ or $\mathrm{BN}$ all rise rapidly, but the thermal conductivities of the composites filled with $\mathrm{Al}_{2} \mathrm{O}_{3}$ or $\mathrm{MgO}$ increase slowly. The thermal conductivity of the composites filled with $\mathrm{SiC}, \mathrm{ZnO}$ or $\mathrm{BN}$ reach respectively 2.85 , 2.26 and $2.08 \mathrm{~W} /(\mathrm{m} \cdot \mathrm{K})$ at a filler content of 60 vol\%. Comparing the thermal conductivities of the composites and that of the fillers, it is not difficult to understand that the thermal conductivity of the filler still have a main effect on the thermal conductivity of the composite at high filler loading (greater than $20 \mathrm{vol} \%$ ) though the ratios of the thermal conductivities of the fillers to that of EVA matrix are all greater than 100. Therefore, the view that there is no significant improvement in the thermal conductivity of the composite when the intrinsic thermal conductivity of the filler is greater than 100 times that of the polymer matrix [16, 14], is valid only for composites with low filler loading (typically less than $15 \mathrm{vol} \%$ ). The law of experimental data can be explained with the geometric mean model, which is valid and suitable for predicting the thermal conductivities of multicomponent systems (Equation (1)) [17]:

$k=k_{m}^{(1-\Phi)} k_{f}^{\Phi}$

where $k, k_{m}$ and $k_{f}$ represent respectively the thermal conductivities of the composites, the polymer matrix and the fillers, $\Phi$ represent the volume fraction of the fillers. According to the equation, the higher the thermal conductivity of the filler, the faster the thermal conductivity of the composite rise with the volume fraction of the filler increasing. The geometric mean model is fairly good agreement with the law of measured thermal conductivities. In this paper, $\mathrm{SiC}, \mathrm{ZnO}$ and $\mathrm{BN}$ are more suitable to be taken for thermally conductive filler than $\mathrm{Al}_{2} \mathrm{O}_{3}$ and $\mathrm{MgO}$.

\subsection{The influence of fillers on the electrical resistivity of EVA composite}

The electrical insulation is a very important property of the encapsulant of a solar cell; therefore, we investigated the influence of different fillers on the electrical resistivity of EVA composite in this paper. Figure 3. shows the bulk electrical resistivity curves of EVA composites filled with different fillers at various volume fractions. It can be seen that the bulk electrical resistivities of EVA composites all increase first and then decrease with the volume fractions of the fillers. At low filler loading, there is no electrical current between the filler particles (by tunneling or hopping) as a result of long distance between the particles, and the potential barrier due to the interfaces are too high for electron hopping. So, the bulk electrical resistivities of composites are high. As the filler load increases and the distance between particles decreases, the electrical current increases, conductive clusters appear resulting in a gradual decrease of the bulk electrical resistivities of the composites [18].

From Figure 3, there are obvious differences between the bulk electrical resistivities of the EVA composites filled with various fillers. The bulk resistivities of the composites filled with $\mathrm{ZnO}$ or $\mathrm{BN}$ decrease slowly, but that with $\mathrm{SiC}$ or $\mathrm{Al}_{2} \mathrm{O}_{3}$ decrease rapidly with rising filler loading. At the

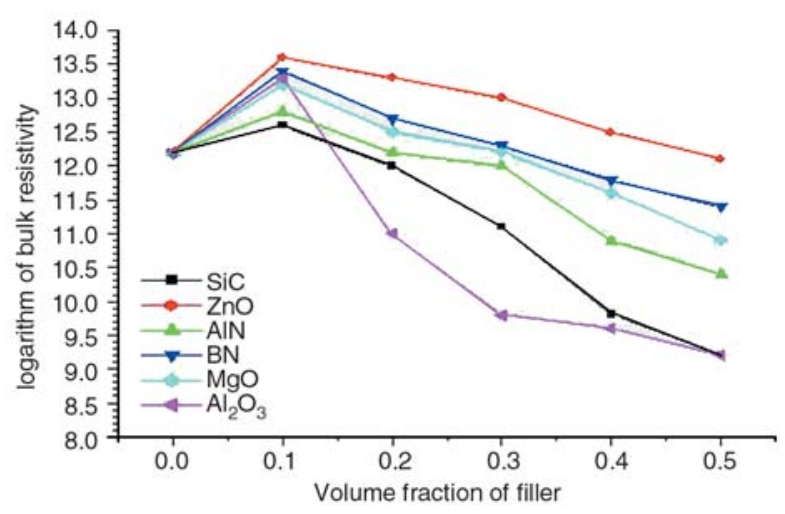

Figure 3. The bulk electrical resistivity of the EVA composites 
volume fraction of 0.5 , the bulk resistivities of the composites filled with $\mathrm{ZnO}$ still maintain $10^{12} \Omega \cdot \mathrm{m}$, but that with $\mathrm{SiC}$ or $\mathrm{Al}_{2} \mathrm{O}_{3}$ decrease to $10^{9} \Omega \cdot \mathrm{m}$. Consequently, from the viewpoint of electrical insulation, $\mathrm{ZnO}$ and $\mathrm{BN}$ are more suitable as a filler of the composite encapsulant than $\mathrm{SiC}$ or $\mathrm{Al}_{2} \mathrm{O}_{3}$ in this paper.

\subsection{The influence of different fillers on the curing degree of the EVA composites}

As one of the important property of encapsulant film of the solar cell, the curing degree ought to reach about $65 \%$ or higher usually. So, in this paper, we also investigated the influence of different fillers on the curing degree of EVA composites. Figure 4 shows the experimental results.

From Figure 4, it can be found out that $\mathrm{SiC}$ and $\mathrm{BN}$ are able to reduce the cross-linking degree of the EVA matrix, but the $\mathrm{ZnO}$ can increase the crosslinking curing degree. The reason of these phenomena is probably that the cross-linking reaction of the EVA matrix is a kind of free radical crosslinking reaction, and the $\mathrm{ZnO}$ known as an activator of the peroxide decomposition may activate the free radical reaction, but $\mathrm{SiC}$ and $\mathrm{BN}$ may have deactivating effect on the free radical reaction. Treated with the coupling agents (KH-560 or OLAT-16), the activating property of the $\mathrm{ZnO}$ and the deactivating properties of the $\mathrm{SiC}$ and $\mathrm{BN}$ all were reduced. So, the cross-linking curing degrees of the EVA composites filled with treated $\mathrm{SiC}$ or $\mathrm{BN}$ all rise; however, that with treated $\mathrm{ZnO}$ decrease.

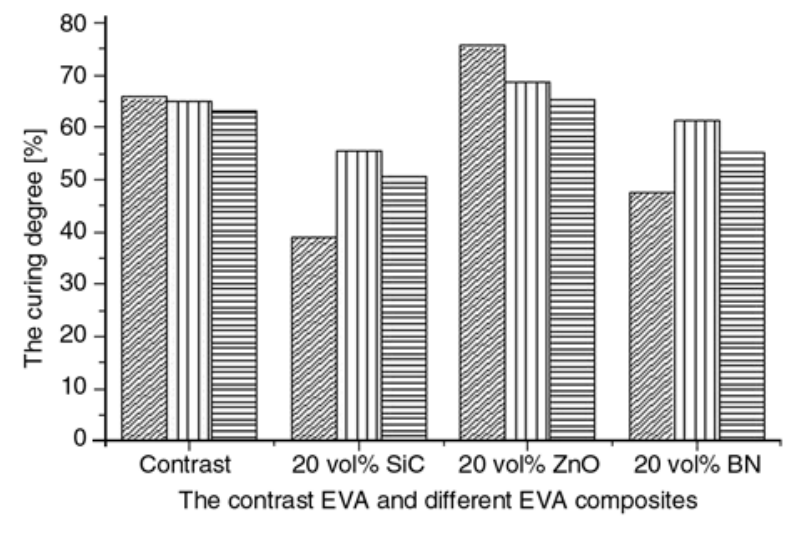

Figure 4. The curing degree of the contrast EVA and different EVA composites

\subsection{SEM of the EVA encapsulating composites filled with fillers}

The SEM of the EVA composites filled with BN (27 vol\%) or $\mathrm{ZnO}(27$ vol\%) are shown in Figure 5 and Figure 6. From those figures, it can be seen that fillers $(\mathrm{BN}$ or $\mathrm{ZnO})$ treated with the coupling agents (KH-560 or OLAT-16) can be dispersed well and compounded effectively in the EVA matrix.

\subsection{The effect of the fillers and couplers on the PV efficiency and heat dissipating ability of the solar cells encapsulated with the EVA composites film on the rear}

Enhancing the PV efficiency of the solar cell is our main aim of improving the EVA encapsulating rear film of the solar cell. So, we investigated the maximum output powers $\left(P_{\max }\right)$ of the solar cells encapsulated with the EVA composite rear films or the

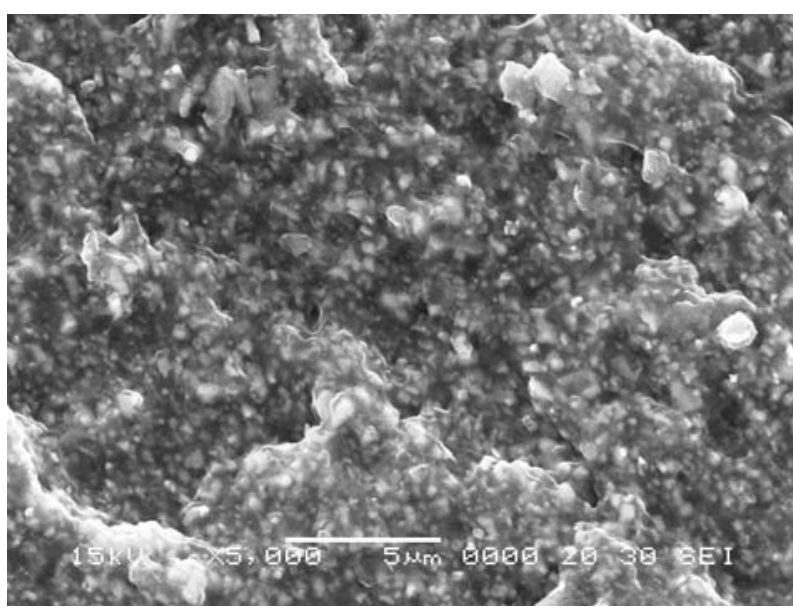

Figure 5. SEM of the EVA composite filled with BN (27 vol\%)

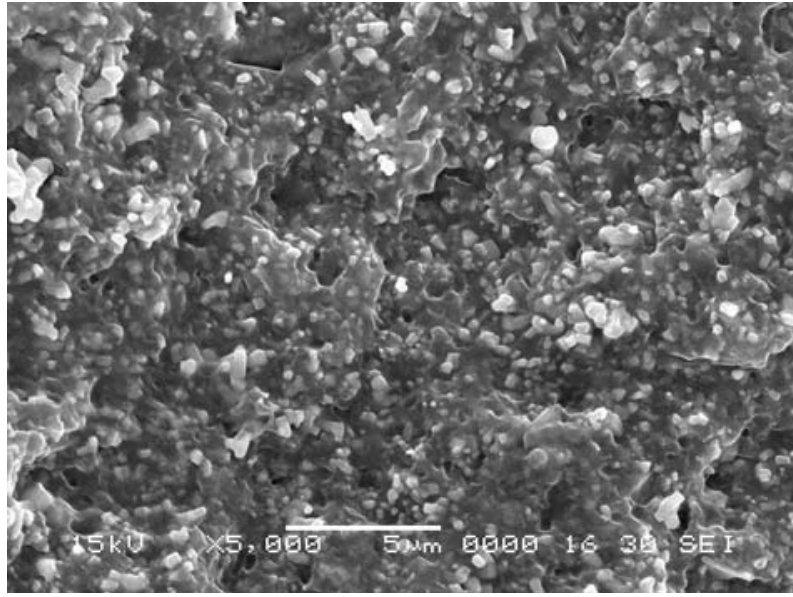

Figure 6. SEM of the EVA composite filled with $\mathrm{ZnO}$ (27 vol\%) 
Table 3. The maximum output power and the surface temperatures of the solar cells

\begin{tabular}{|l|c|c|c|c|c|c|}
\hline \multicolumn{1}{|c|}{ Rear film } & Reference & $\begin{array}{c}\mathbf{2 0} \text { vol\% SiC } \\
(\mathbf{K H}-560)\end{array}$ & $\begin{array}{c}\mathbf{2 0} \text { vol\% BN } \\
(\mathbf{K H}-560)\end{array}$ & $\begin{array}{c}\mathbf{2 0} \text { vol\% ZnO } \\
\text { (KH-560) }\end{array}$ & $\begin{array}{c}\mathbf{2 0} \text { vol\% ZnO } \\
\text { (OLAT-1618) }\end{array}$ & $\begin{array}{c}\mathbf{1 0} \text { vol\% ZnO } \\
\text { (KH-560) }\end{array}$ \\
\hline $\mathrm{P}_{\max }[\mathrm{W}]$ & 5.15 & 5.25 & 5.29 & 5.41 & 5.10 & 5.23 \\
\hline$\Delta \mathrm{P} / \mathrm{P}[\%]$ & 0 & 1.94 & 2.72 & 5.05 & -0.97 & 1.55 \\
\hline $\mathrm{T}_{2}$ (upper) $\left[{ }^{\circ} \mathrm{C}\right]$ & 44.8 & 44.2 & 44.2 & 43.8 & 44.4 & 44.6 \\
\hline $\mathrm{T} 3(\mathrm{rear})\left[{ }^{\circ} \mathrm{C}\right]$ & 45.4 & 48.6 & 47.2 & 47.8 & 46.6 & 46.4 \\
\hline$\Delta \mathrm{T}\left(\mathrm{T}_{3}-\mathrm{T}_{2}\right)\left[{ }^{\circ} \mathrm{C}\right]$ & 0.6 & 4.4 & 3.0 & 4.0 & 2.2 & 1.8 \\
\hline
\end{tabular}

reference EVA rear film (Bridgestone) under given irradiation intensity $\left(1000.0 \mathrm{~W} / \mathrm{m}^{2}\right)$. The surface temperatures of the solar cells also were measured after outdoor exposed $2 \mathrm{~h}$. The test results shown in Table 3.

From Table 3, we can find out that various couplers and thermally conductive fillers have different effect on the PV efficiency and heat dissipating ability of the solar cell, the composite rear film mixed with KH-560 and the thermal conductive fillers improve the maximum output powers of the solar cells effectively, the maximum rate of the cell output power increase reaches $5.05 \%$; but the composite encapsulating rear film treated with OLAT1618 caused the maximum output power of the solar cell decrease slightly, and yellowing obviously after high temperature curing. It can also be seen that the composite encapsulated rear film filled with thermal conductive fillers allow the increase of the rear surface temperature $\left(T_{3}\right)$ and the difference between $T_{2}$ and $T_{3}(\Delta T)$. It indicate that the composite encapsulated rear film has more effective heat dissipating ability than the reference EVA film at the same ambient temperature. Several other factors, such as the properties of the silicon, light reflection, the temperature of cell and the insulation of encapsulant etc, can effect the PV efficiency of the solar cell [19]. From the test results, the EVA composite encapsulating rear film filled with the thermal conductive fillers and KH-560 enhance the PV efficiency and heat dissipating ability of the solar cell effectively.

\section{Conclusions}

Filling with thermally conductive fillers can enhance the thermal conductivity of the composites effectively. The thermal conductivity of the filler exert a major effect on the thermal conductivity of the composite at high filler loading (greater than $20 \mathrm{vol} \%$ ). The thermal conductivities of the EVA composites filled with $\mathrm{SiC}, \mathrm{ZnO}$ or $\mathrm{BN}$ reach respectively $2.85,2.26$ and $2.08 \mathrm{~W} /(\mathrm{m} \cdot \mathrm{K})$ at a filler content of $60 \mathrm{vol} \%$. The EVA composites filled with $\mathrm{ZnO}$ or $\mathrm{BN}$ have more superior electrical insulation than that those filled with $\mathrm{SiC}$ or $\mathrm{Al}_{2} \mathrm{O}_{3}$. $\mathrm{ZnO}$ can promote the cross-linking reaction of the EVA matrix, but $\mathrm{SiC}$ and $\mathrm{BN}$ reduce the cross-linking curing degree of the EVA matrix. Treated with the coupling agents (KH-560 or OLAT-16), the fillers (BN or $\mathrm{ZnO}$ ) can be dispersed well and compounded effectively in the EVA matrix . The EVA composite encapsulating rear films filled with suitable coupler and thermally conductive fillers are able to improve the PV efficiency and the heat dissipating ability of the solar cell effectively.

\section{References}

[1] Sun S-S., Sariciftci N. S.: Organic photovoltaics: Mechanisms materials and devices. CRC Press, Boca Raton (2005).

[2] Bube R. H.: Photovoltaic materials. Imperial College Press, London (1998).

[3] Tripanagnostopoulos Y., Nousia T., Souliotis M., Yianoulis P.: Hybrid photovoltaic/thermal solar system. Solar Energy, 72, 217-234 (2002).

[4] Royne A., Dey C. J., Mills D. R.: Cooling of photovoltaic cells under concentrated illumination: A critical review. Solar Energy Materials and Solar Cells, 86, 451-483 (2005).

[5] Fraisse G., Ménézo C., Johannes K.: Energy performance of water hybrid PV/T collectors applied to combisystems of direct solar floor type. Solar Energy, 81, 1426-1438 (2007).

[6] Brinkworth B. J., Cross B. M., Marshall R. H., Yang H.: Thermal regulation of photovoltaic cladding. Solar Energy, 61, 169-178 (1997).

[7] Huang B. J., Lin T. H., Huang W. C., Sun F. S.: Performance evalution of solar photovoltaic/thermal systems. Solar Energy, 70, 443-448 (2001).

[8] Rockendorf G., Sillmann R., Podlowski L., Litzenburger B.: PV-hybrid and thermoelectric collectors. Solar Energy, 67, 227-237 (1999). 
[9] Sandnes B., Rekstad J.: A photovoltaic/thermal (PV/T) collector with a polymer absorber plate. Experimental study and analytical model. Solar Energy, 72, 63-73 (2002).

[10] Royne A., Dey C. J.: Design of a jet impingement cooling device for densely packed PV cells under high concentration. Solar Energy, 81, 1014-1024 (2007).

[11] Lu Z. H., Yao Q.: Energy analysis of silicon solar cell modules based on an optical model for arbitrary layers. Solar Energy, 81, 636-647 (2007).

[12] Procter P., Solc J.: Improved thermal conductivity in microelectronic encapsulants. in' Proceedings of $41^{\text {st }}$ Electronic Components and Technology Conference, Atlanta, USA' 835-842 (1991).

[13] Bujard P., Kuhnlein G., Ino S., Shiobara T.: Thermal conductivity of molding conpounds for plastic packaging. in' Proceedings of $44^{\text {th }}$ Electronic Components and Technology Conference, Washington, USA', 159-163 (1994).
[14] Lee G-W., Park M., Kim J., Lee J. I., Yoon H. G.: Enhanced thermal conductivity of polymer composites filled with hybrid filler. Composites, Part A: Applied Science and Manufacturing, 37, 727-734 (2006).

[15] Ma Q. F., Fang R. S., Ciang L. C., Guo S.: Handbook of thermophysical properties (in Chinese). Chinese Agricultural Machinery Press, Beijin (1986).

[16] Bhattacharya S. K.: Metal-filled polymers. Marcel Dekker, New York (1986).

[17] Dawson D. M., Briggs A.: Prediction of the thermal conductivity of insulation materials. Journal of Materials Science, 16, 3346-3356 (1981).

[18] Huang J-C.: Carbon black filled conducting polymers and polymer blends. Advances in Polymer Technology, 21, 299-313 (2002).

[19] Zweibel K.: Basic photovoltaic principles and methods. Van Nostrand Reinhold Press, New York (1984). 